\title{
Influencing Factors on Modest Fashion Market: A Case Study
}

\author{
Maha Radwan ${ }^{1, *}$; Mohamad Kamal ${ }^{2}$; Sepideh Khavarinezhad ${ }^{3}$ and Davide Calandra ${ }^{4}$ \\ 1,* Maha Radwan, Department of Management, University of Turin, Italy \\ ${ }^{2}$ Mohamed Kamal, Department of Management, University of Turin, Italy \\ ${ }^{3}$ Sepideh Khavarinezhad, Department of Management, University of Turin, Italy \\ ${ }^{4}$ Davide Calandra, Department of Management, University of Turin, Italy
}

\begin{abstract}
The modest fashion from the Islamic point of view is an emerging phenomenon that offers non-adherent and non-transparent clothes that cover a large part of the body respecting the religious dictates. It is seen as a growing industry in the fashion sector and has spread throughout the world bringing the attention of global fashion houses and famous designers. The objective of this paper is to define a new economic opportunity for the fashion sector represented by Muslim consumers and to investigate the influence of Islamic ethical and moral standards in the fashion which is defined by Shariah to better understand and meet the Muslim needs in this market. From the religious, ethical perspective the study also focuses on the cultural, social and regulative aspect of Muslims some of these elements are considered extremely varied and include needs and tastes that are different from one environment to another. To get this done, the institutional theory has been employed to systematically investigate the factors Influencing on the modest fashion. This paper takes advantage of case study methodology looking to the Italian context. Our findings stress the importance of the modest fashion in Italy due to the increase of Muslims in the country as well as the interest of the Italian companies in the national and international modest fashion market. Findings also highlight that despite the interest of Italian companies to provide modest fashion products, a large segment of Muslims in Italian market adopts traditional methods to cover their needs and also the Islamic countries markets are still largely untapped by many Italian designers and clothing companies. The study contributes by proposing some influential factors taken from the institutional theory to understand the market needs and in order to access it.
\end{abstract}

Keywords: Modest Fashion, Institutional theory' factors, Italy 